\title{
A integração curricular para a concretização da educação na perspectiva da formação integral em uma escola de educação profissional no Ceará
}

\author{
Curricular integration for the achievement of education from the \\ perspective of integral training in a professional education school in
}

Ceará

\section{Integración curricular para el logro de la educación desde la perspectiva de la formación Integral en una escuela de educación profesional en Ceará}

José Fábio Vieira de Oliveira'

https://orcid.org/0000-0003-1812-1479

Lucas Melgaço da Silva²

https://orcid.org/0000-0003-4|45-4036

Resumo: O presente artigo visa refletir sobre a relevância da integração curricular na perspectiva da formação integral em uma escola de educação profissional no estado do Ceará. Para tanto, investiga como se dá essa integração entre as bases técnica e regular, e como tem se desenvolvido, considerando a integralidade da formação dos jovens atendidos por essa modalidade de ensino. Por se tratar de um estudo de caso com viés qualitativo, utiliza entrevistas estruturadas como instrumento de pesquisa, as quais foram realizadas com 5 professores, 7 alunos, 3 coordenadores e I diretor escolar. A partir dos resultados da pesquisa, fica evidente 0 distanciamento entre a educação básica geral e a educação profissional, permanecendo essa dualidade. Percebese uma dificuldade de implementação de uma Educação Profissional Integrada que seja efetiva no sentido dessa articulação, para que o sujeito seja formado na sua ampla capacidade física, intelectual e tecnológica. Esse distanciamento dificulta a integração curricular e o trabalho com esses jovens na perspectiva da formação integral. Surge a necessidade de se pensar estratégias e práticas que ampliem essa integração, primordialmente, por meio do estudo dos currículos dos cursos ofertados pela instituição e das reuniões pedagógicas de integração entre os eixos profissional e regular.

Palavras-chave: Integração curricular. Formação integral. Educação profissional.

Abstract: This article aims to reflect on the relevance of curricular integration from the perspective of comprehensive training in a Professional Education school in the state of Ceará. To that end, it investigates how

\footnotetext{
I Mestre em Gestão e Avaliação da Educação Pública pela Universidade Federal de Juiz de Fora (UFJF). Professor da Rede Estadual de Educação do Ceará. E-mail: josefabiooliveira2015@gmail.com

2 Doutor em Educação Brasileira (UFC). Professor do Centro Universitário Christus e Docente Externo da Universidade Federal do Ceará. E-mail: lucasmelgaco@alu.ufc.br
} 
this integration takes place between the technical and regular bases, and how it has developed considering the integrality of the training of teenager served by this type of education. As it is a case study with a qualitative bias, it uses structured interviews as a research instrument, which were conducted with 5 teachers, 7 students, 3 coordinators and I school principal. From the results of the research, the distance between general basic education and professional education is evident, with this duality remaining. It is perceived a difficulty in implementing an Integrated Professional Education that is effective in the sense of this articulation, so that the subject is trained in its broad physical, intellectual and technological capacity. This distance makes it difficult to integrate the curriculum and work with these students from the perspective of comprehensive training. The need arises to think of strategies and practices that expand this integration, primarily through the study of the curricula of courses offered by the institution and pedagogical meetings for integration between the professional and regular axes.

Keywords: Curricular integration. Integral training. Professional education.

Resumen: Este artículo tiene como objetivo reflexionar sobre la relevancia de la integración curricular desde la perspectiva de la formación integral en una escuela de Educación Profesional del estado de Ceará. Por lo tanto, investiga como se da esta integración entre la base técnica y la regular, y como se ha desarrollado considerando la integralidad de la formación de los jóvenes atendidos por este tipo de educación. Al tratarse de un estudio de caso con sesgo cualitativo, utiliza entrevistas estructuradas como instrumento de investigación, las cuales se realizaron con 5 docentes, 7 alumnos, 3 coordinadores y I director de escuela. A partir de los resultados de la investigación, se evidencia la distancia entre la educación básica general y la educación profesional, quedando esta dualidad. Se percibe una dificultad para implementar una Educación Profesional Integrada que sea efectiva en el sentido de esta articulación, de manera que el sujeto se forme en su amplia capacidad física, intelectual y tecnológica. Esta distancia dificulta la integración curricular y el trabajo con estos jóvenes desde la perspectiva de la formación integral. Surge la necesidad de pensar en estrategias y prácticas que amplíen esta integración, principalmente a través del estudio de los planes de estudio de los cursos que ofrece la institución y encuentros pedagógicas para la integración entre los ejes profesional y regular.

Palabras-clave: Integración curricular. Formación integral. educación profesional.

\section{Introdução}

A relação trabalho e educação sempre foi objeto de disputa no sistema capitalista, e as lutas por uma mudança devem avançar junto a outras batalhas sociais, objetivando a melhoria de vida da população. A educação deve servir para a humanização e não apenas para a exploração a serviço do mercado (CIAVATTA, 20I4). Com o intuito de alcançar o desenvolvimento econômico e minorar as desigualdades sociais, aposta-se na ampliação da oferta do ensino médio integrado à educação profissional, objetivando superar o dualismo estrutural da sociedade e da educação brasileira, a divisão de classes sociais, a divisão entre formação para o trabalho manual ou para o trabalho intelectual, em defesa da democracia e da escola pública.

O estado do Ceará, em 2007, aderiu ao Programa Brasil Profissionalizado com o Decreto $n^{\circ}$ 6.302, de 12 de dezembro de 2007, e instituiu, em 2008, as Escolas Estaduais de Educação Profissional (EEEPs), por meio da Lei ${ }^{\circ} 14.273$, de 19 de dezembro de 2008, publicada no Diário Oficial do Estado de 23 de dezembro de 2008. O decreto inovou o ensino médio cearense com a implantação de escolas profissionais de tempo integral. A organização curricular ocorre na modalidade integrada, ou seja, contempla a formação geral em consonância com a Base Nacional Comum Curricular (BNCC) e a formação profissional, estruturada de forma específica para os diversos cursos ofertados. Além disso, 
existem outros componentes, tais como: formação para a cidadania, mundo do trabalho, empreendedorismo e projeto de vida, que objetivam favorecer a formação integral dos estudantes.

As EEEPs foram criadas em consonância com o Programa Aprender pra Valer, o qual articula e integra o ensino médio à educação profissional como uma de suas formas de efetivação. Para tanto, foi necessária a revisão dos currículos do ensino médio, possibilitando aos alunos a integração ao mundo contemporâneo nas dimensões fundamentais da cidadania e do trabalho. Essa proposta organizacional deveria dar significado ao conhecimento escolar, mediante à contextualização, e evitar a compartimentalização de áreas, ao utilizar a interdisciplinaridade com incentivo do raciocínio e a capacidade de aprender do jovem.

Dentre os principais objetivos do currículo integrado destacam-se: diminuir a fragmentação do conhecimento oferecido aos alunos; promover a interdisciplinaridade e a integração das componentes curriculares; relacionar o âmbito social à prática social concreta; formação integral do ser humano em todos os aspectos, centrando o relacionamento da cultura com o mundo do trabalho; trabalho como princípio educativo; tornar os trabalhadores capazes de atuar como dirigentes e cidadãos, superando a dicotomia manual/intelectual; pesquisa como princípio pedagógico e aprendizagem orientada para a autonomia do aluno (RAMOS, 20I0).

Acredita-se que a integração curricular produz reverberações na formação integral dos discentes, contribuindo para um processo de aprendizagem significativa. Portanto, o objetivo desse artigo é refletir sobre a relevância da integração curricular na perspectiva da formação integral em uma escola de educação profissional no estado do Ceará. Para tanto, investiga-se como isso tem sido feito entre as bases técnica e regular, e como tem se desenvolvido, considerando a integralidade da formação dos jovens atendidos por essa modalidade de ensino.

O estudo se justifica na necessidade de discutir a importância da integração curricular nas práticas pedagógicas desenvolvidas no âmbito escolar, de modo a compreender como a implantação da Educação de Tempo Integral e Integrada pode colaborar para a formação integral dos estudantes. Inicialmente, foi feita uma breve discussão acerca da temática educação integral, currículo integrado e educação em tempo integral, seguida da apresentação do percurso metodológico. $O$ tópico que apresenta os resultados e as discussões aparece na sequência. Por fim, apresentam-se as considerações sobre os achados da pesquisa.

O presente trabalho é um recorte de uma dissertação de mestrado desenvolvida no Programa de Pós-graduação Profissional em Gestão e Avaliação da Educação Pública da Universidade Federal de Juiz de Fora (UFJF), intitulada "Educação Profissional e Qualidade Educacional: desafios e possibilidades de estratégias de gestão e de ensino no Ceará”, sob a orientação da Prof. Dra. Rosângela Veiga Júlio Ferreira. 


\section{A educação integral e a participação dos estudantes}

As políticas de educação integral e em tempo integral se apresentam como formas de enfrentamento às desigualdades sociais. Entende-se por educação integral, aquela desenvolvida para a formação múltipla do sujeito, enquanto a educação em tempo integral é entendida pela perspectiva de ampliação da jornada escolar (DARCY RIBEIRO, 20I7). Projetos com esse viés configuram-se como políticas de equidade, podendo oferecer mais oportunidades a quem tem menos. Para isso, utilizam critérios de vulnerabilidade, posto que as crianças e as jovens acompanhadas, geralmente, são oriundas de famílias atendidas por programas sociais, que vivem à margem da sociedade.

A escola em tempo integral é uma opção a ser seguida na ampliação das possibilidades para trabalhar o sujeito na sua integralidade. Logo, dar-se-á por meio do ensino-aprendizagem, na consideração das emoções, dos sentimentos, da ética e da estética (DARCY RIBEIRO, 2017). Isso demanda um esforço coletivo de todos que compõem a instituição escolar: docentes, discentes, família e comunidade.

A ampliação e a diversificação da oferta do ensino médio em várias formas e modalidades visa estruturar a escola pública para que consiga contrariar a relação entre situação econômica do aluno e desempenho acadêmico. As escolas integrais com jornada ampliada, por exemplo, configuram-se como uma estratégia de proteção social, na promoção da equidade educacional, da profissionalização, da eficácia acadêmica e da formação humana plena (KRAWCZYK, 20I4).

Para a efetiva implementação da proposta de escola em tempo integral, é preciso romper com alguns paradigmas que ainda se fazem presentes na educação, principalmente os que se referem à questão do tempo, do espaço e do currículo, atribuindo novas ressignificações a esses elementos. Nesse sentido, projeta-se uma instituição onde o espaço de aprendizagem não se limite à sala de aula, o tempo não se reduza simplesmente à ampliação de um turno escolar, e o currículo ocupe outras disciplinas que são inerentes à formação integral e ao desenvolvimento pleno dos jovens.

As juventudes são diversas e complexas. Ser jovem se define pelas suas práticas e pelas formas de se relacionar com a família, com os amigos; na rua, no trabalho e na escola. Essa última, abriga as esferas anteriores como retrato do mundo. Assim, olhar para essa diversidade e construir aprendizagens é reconhecer o jovem em todas as suas dimensões. Fala-se, então, em uma educação com foco nas singularidades dos indivíduos e dos territórios.

Juarez Dayrell (2007) apresenta alguns desafios no trabalho com as juventudes: como garantir mecanismos de escuta e compreensão das demandas e das necessidades dos setores juvenis? Como capacitar melhor o jovem para o desenvolvimento de ações coletivas autônomas que busquem a garantia de seus direitos? Como construir políticas e práticas que visem a igualdade social e ao mesmo tempo contemplem a diversidade do mundo juvenil? Como construir uma metodologia que vá ao 
encontro das necessidades e das demandas do jovem? Frente a esses desafios, o autor argumenta a necessidade de a escola repensar sua proposta educativa voltada às massas, disciplinadora e homogeneizante, no entanto, que se constitui em um contexto flexível, individual e, ao mesmo tempo, plural. Portanto, caberia aos professores uma postura de diálogo e interlocução ante as crises e as dúvidas que o jovem carrega na constituição do seu eu.

Nessa perspectiva, a educação passa a ter uma visão mais ampla. Não se trata de instruir, mas de formar: habilidades, visões de mundo, sendo central o estímulo à curiosidade, passando de espontânea para epistemológica. Para tal, é preciso tornar o jovem um interlocutor válido, fazendo-se necessária uma escuta ativa para adequar conteúdos, ritmos e tempos à realidade e, com isso, potencializar as experiências de vida que eles trazem, ampliando os tempos e os espaços humanizadores, percebendo-os como pessoas em formação, com direito de ser e viver a sua juventude.

A educação integral, nesse contexto, pode ampliar o tempo, mas, sobretudo, os espaços e as atividades de interesse desses indivíduos. Ela é estruturada a partir do desejo do jovem, da construção do seu conhecimento, de suas experiências e de suas formas de participação. Quando o desejo dele entra em cena, o trabalho do professor fica ainda mais importante e criativo. Cada componente curricular torna-se fundamental para organizar os saberes e estimular a curiosidade na constituição de uma aprendizagem mais significativa.

A escola é entendida como um espaço singular, configurando-se como um ponto de encontro e convivência fundamental na vida do jovem. Isto posto, espera-se que ela articule os saberes locais, a escuta, o diálogo com a comunidade e com toda a diversidade do seu entorno, sendo isso uma das opções para promover a educação integral. A cidade deve ser percebida como um direito, com uma gama de possibilidades que serão descobertas a partir da circulação e da exploração pelos jovens para ampliação de seus repertórios.

Esse modelo apresenta uma concepção de educação que coloca o aluno no centro do processo e busca seu desenvolvimento em todas as dimensões: física, emocional, intelectual, cultural e social, ou seja, a educação que tem relação com a vida, que prepara o indivíduo para o seu desempenho na sociedade, com bases éticas e solidárias. Isso implica na construção de um currículo integrado, em que o professor atua como mediador e garante a intencionalidade educativa.

Vale destacar que o currículo deve ser entendido como aquilo que compreende e direciona as experiências educacionais desenvolvidas pela escola e vivenciadas pelos estudantes. É nele que estão os conteúdos e as metodologias abordadas no decorrer do processo de ensino e aprendizagem. Por isso, deve-se considerar o atual contexto de discussão sobre os conteúdos escolares que devem ser contemplados no currículo, tendo em vista a percepção de influências diretas no ensino, no desenvolvimento das práticas pedagógicas dos professores e na organização do trabalho escolar. 
Em uma perspectiva de currículo integrado, temática de abordagem deste estudo, incorporamse a essa formação geral um viés técnico e político ao tempo que valoriza os saberes cotidianos dos alunos, propicia maior iniciativa dos sujeitos, suprime a visão hierárquica e dogmática do conhecimento, além de conceber o trabalho como princípio educativo (RAMOS, 2009).

Segundo Krawczyk (20lI), na maioria das vezes, a atração ou a rejeição dos alunos por uma ou por outra disciplina está vinculada à experiência e aos resultados escolares. Isso recai sobre a atitude do docente: seu modo de ensinar; a paciência com os alunos; e a capacidade de estimulá-los e dialogar com eles. Sua atuação torna-se decisiva no processo de ensino e aprendizagem dos discentes.

Uma escola orientada para a educação integral, necessariamente, busca a participação de todos os envolvidos, promove o diálogo e ultrapassa os limites do espaço escolar e se apropria do bairro e da cidade. Para garantir o desenvolvimento pleno de todos os estudantes, é preciso o engajamento de múltiplos setores, a chamada intersetorialidade, através de políticas públicas adequadas.

O desenvolvimento pleno dos indivíduos é um direito previsto na Constituição. O papel da educação integral é garantir que todos tenham as ferramentas necessárias para seguir aprendendo, tornando-se cidadãos autônomos capazes de construir seus próprios projetos de vida. Para isso, é preciso ampliar e qualificar o tempo, o espaço e o currículo, diversificando os conteúdos e abrindo um leque de possibilidades. Não se trata, pois, de aumentar a carga horária de determinados componentes curriculares. O currículo é sempre uma escolha. Quando a escola define como e o que ofertar aos seus alunos, revela suas pretensões de futuro.

\section{Metodologia}

Como metodologia, optou-se por utilizar entrevistas estruturadas como instrumento de pesquisa, por se tratar de um estudo de caso com viés qualitativo. Logo, a descrição e a delimitação dos participantes da pesquisa constituem um problema a ser enfrentado de imediato, já que se trata de parte importante da análise de campo. Vale salientar que esse processo de aplicação dos instrumentos, com todos os participantes, foi realizado através de web conferências, no Google Meet e/ou WhatsApp, devido ao período de isolamento social, por conta da pandemia da COVID-19, iniciada durante o primeiro semestre de 2020.

Utilizaram-se as entrevistas estruturadas como instrumento de pesquisa para a coleta de dados, na busca de compreender a percepção dos sujeitos e suas subjetividades. Uma das principais características da entrevista estruturada é a utilização de um roteiro previamente elaborado, apresentando foco em determinados assuntos. Contudo, esse roteiro não deve ser engessado. Segundo Vergara (2009), o roteiro servirá de guia para que se possa obter a resposta que reflita a posição do entrevistado e possibilite responder ao problema de investigação. 
Vale ressaltar que optou-se em manter o anonimato da instituição escolar por questões éticas, ao referir-se à escola, chamar-se-á de EEEP Gama, entretanto far-se-á uma breve caracterização da escola para situar o contexto local. A EEEP Gama localiza-se no interior do Ceará. Segundo dados do IBGE, o município onde a escola está situada está entre os mais vulneráveis do estado e não possui indústrias. Economicamente, a cidade, com uma população estimada, em 2018, de 18.945 habitantes, tem como base a agricultura e o comércio. Além dessas características, a escola encontra-se inserida em um bairro periférico e atende a um universo bastante distinto, recebendo estudantes de diferentes níveis econômicos. Apesar desse elemento, cabe destacar que a maioria do seu alunado provém das classes consideradas como mais baixas, recebendo estudantes da zona rural do município, de diferentes localidades e de municípios circunvizinhos.

Para o desenvolvimento deste trabalho, realizou-se uma série de entrevistas com atores de diferentes segmentos que compõem a instituição escolar, a saber: um diretor escolar, três coordenadores pedagógicos, cinco professores e sete estudantes. A escolha desses atores para a realização das entrevistas é justificada pelo fato de que eles estão envolvidos diretamente nos processos escolares. Dessa forma, a integração curricular e os processos pedagógicos voltados para a formação integral fazem parte do cotidiano desses sujeitos.

As entrevistas foram realizadas de forma virtual nos meses de abril e maio de 2020. Para a realização delas, utilizou-se um roteiro estruturado, com a inclusão de questões voltadas para o entendimento de como a implantação da Educação de Tempo Integral e Integrada pode colaborar para a formação integral dos estudantes.

As primeiras entrevistas foram realizadas com uma amostra dos professores da escola. Para tanto, selecionaram-se um total de 05 , sendo 04 da base regular (um em cada área do conhecimento: Linguagens e Códigos, Ciências Humanas, Ciências da Natureza e Matemática), e 01 da base técnica. Este trabalho teve como objetivo compreender os sentidos atribuídos por eles à escola que pertencem, buscando identificar como relacionam seus respectivos projetos e as ações ao movimento empreendido pela gestão e pelos seus colegas para a melhoria da aprendizagem, como também conhecer melhor o ponto de vista sobre a temática em estudo. Esclarece-se, ao leitor, que neste artigo refere-se a docentes como PROFESSOR LINGUAGENS, PROFESSOR HUMANAS, PROFESSOR NATUREZA, PROFESSOR MATEMÁTICA e PROFESSOR TÉCNICO, para manter o anonimato dos participantes da pesquisa.

Para a realização das entrevistas com os estudantes, selecionou-se uma amostra de 07 alunos do $3^{\circ}$ ano do ensino médio, visto que eles estão há mais tempo na escola e têm um conhecimento maior dos projetos e das ações desenvolvidos, já que a maioria dessas atividades são voltadas para essa série, por ser a que é avaliada através das avaliações externas (SAEB, SPAECE e ENEM). A entrevista 
coletiva com os alunos teve como objetivo compreender os sentidos atribuídos pelos estudantes aos projetos desenvolvidos pela escola, considerando a relevância das opiniões para diagnosticar desafios e possibilidades das estratégias pedagógicas e gestoras desenvolvidas pela escola. Da mesma maneira que os professores, refere-se aos estudantes como ALUNO I a ALUNO 7.

Para a participação dos estudantes, o pesquisador enviou mensagens via WhatsApp, convidando-os a participar da pesquisa, juntamente com o Termo de Consentimento para apreciação dos seus responsáveis. Após a aceitação e o consentimento, criou-se um grupo de WhatsApp, em que eles foram adicionados. Assim, à medida que se faziam os questionamentos, os alunos respondiam através de áudios e digitações, de forma síncrona. llustra-se que a manutenção dos estudantes durante esse período teve como objetivo garantir as suas respostas sem possíveis interferências de outros.

Por fim, realizaram-se entrevistas com os gestores escolares. Nessa categoria, foram entrevistados o diretor e os três coordenadores escolares, um da área de Linguagens e Códigos, um da área de Humanas e outro da área de Ciências da Natureza e Matemática, a fim de compreender as percepções desses atores sobre as práticas gestoras e docentes desenvolvidas na escola, na perspectiva do trabalho com metas, gestão por resultados, trabalho colaborativo, protagonismo docente e discente, como também os desafios de gerir uma escola que apresenta bons índices educacionais. Quando se referir aos gestores, serão citados como COORDENADOR I, COORDENADOR 2, COORDENADOR 3 e DIRETOR.

\section{Questões Éticas}

Mainardes e Cury (2019), no documento da Associação Nacional de Pós-Graduação e Pesquisa em Educação (ANPED), intitulado "Ética e pesquisa em educação: subsídios", apontam a crescente demanda de pesquisa em ciências sociais e humanas e destacam as discussões sobre suas particularidades. Tais proposições culminam com a necessidade de diferenciar as abordagens sobre ética na pesquisa nessa área com a da saúde. Segundo os autores, a ANPED, enquanto associação que congrega os pesquisadores da educação, tem potencial para deliberar princípios e padrões éticos, quais sejam:

a) todas as pesquisas que envolvam seres humanos devem ter como princípio fundante a dignidade da pessoa humana. Isso implica no respeito aos participantes, consentimento, avaliação cuidadosa de potenciais riscos aos participantes, compromisso com o benefício individual, social e coletivo das pesquisas;

b) respeito aos direitos humanos e à autonomia da vontade;

c) emprego de padrões elevados de pesquisa, integridade, honestidade, transparência e verdade;

d) defesa dos valores democráticos, da justiça e da equidade; e

e) responsabilidade social (MAINARDES; CURY, 2019, p. 27). 
Uma vez que o resultado da submissão do projeto de pesquisa ao Comitê Nacional de Ética não ocorreu em tempo hábil e existia um prazo limite para conclusão do trabalho que originou o presente texto, não foi possível obter o parecer final de aprovação. Entretanto, com base nas dificuldades observadas no desenvolvimento da pesquisa em ciências sociais e humanas, destacadas pelos autores ora citados, além da garantia dos princípios e dos padrões éticos da ANPED, considerados na assinatura de um "Termo de Livre Esclarecido" por todos os sujeitos, a pesquisa foi aprovada para apresentação dos resultados obtidos a partir dos instrumentos de coleta de dados.

Na próxima seção, far-se-á a análise dos dados advindos das entrevistas estruturadas realizadas com os sujeitos, levando em conta os aspectos relativos à Educação de Tempo Integral e Integrada na perspectiva da formação integral.

\section{Resultados e/ou Discussões}

Nas Escolas Estaduais de Educação Profissional do Ceará existe uma proposta de modalidade de ensino de tempo integral e integrada: tempo integral, na perspectiva de ampliação do tempo pedagógico, em que o aluno passa o dia todo na escola; integrada, na perspectiva de que deve integrar a base regular (ensino propedêutico) e a base técnica (ensino profissionalizante). Contudo, essa perspectiva se apresenta como hipótese, visto que os dados da pesquisa mostram que essa modalidade de ensino tem sido entendida apenas como tempo integral.

Esse fenômeno apresenta-se nos questionamentos aos diferentes atores da instituição acerca de como eles percebem essas práticas no cotidiano escolar, tendo em mente a integração do eixo regular e do técnico, além do que poderia ser feito para melhorar e efetivar essa integração, ampliando os debates pedagógicos.

[...] há uma forte separação entre o eixo profissional e o eixo regular[...] Posso dizer que não seja pelo diretor, mas pelo próprio sistema, vem de cima para baixo essa cobrança, então, quando há essa diferenciação cria-se grupos e cria-se injustiças: eu cobro de você isso e não cobro do outro aquilo. Eu dou mais atenção àquele tema em detrimento do outro tema. Por exemplo, se eu faço reunião e discuto planejamento, tem que discutir planejamento no eixo profissional e no eixo regular. Tem que haver uma unidade, tem que ter a paridade, o eixo profissional com o eixo regular deve ser tratado com paridade[...] (PROFESSOR TÉCNICO, Entrevista, 2020).

Percebe-se, pela fala do professor, que há uma diferenciação no tratamento entre os dois eixos e cita-se a importância de serem tratados com igualdade. Essa fragmentação não colabora para o bom desenvolvimento das ações e não favorece os debates pedagógicos, fragilizando a perspectiva da educação integral. Trabalhar o aluno na sua integralidade demanda um esforço coletivo de todos que compõem a instituição escolar, o que é dificultado pelo problema acima citado. 
Para Gadotti (2009, p. 97), “o princípio geral da educação integral é o da integralidade. O conceito de integralidade refere-se à base da educação, que deve ser integral, omnilateral e não parcial e fragmentada." O autor destaca que, "para trabalhar de modo integrado, exige-se o relacionamento de profissionais de diferentes formações, envolvidos num processo comum.” (p. 102). Depreende-se que, para alcançar a integralidade, é necessário um trabalho conjunto e articulado entre os professores da base profissional e da base regular, demandando maior unidade entre esses profissionais, favorecendo a formação múltipla e plural dos discentes. Ainda sobre esse aspecto, outro professor assim se manifesta:

A integração curricular já foi tentada, mas não teve a eficiência que se buscava. $O$ que pode ser colocado para ampliação do debate pedagógico, seria que a proposta político-pedagógica da escola fosse criada, conciliando o planejamento participativo, tanto da base regular quanto da técnica (PROFESSOR HUMANAS, Entrevista, 2020).

Sobre essa temática, Gadotti (2009, p. 98) argumenta: “numa escola de tempo integral[...], o currículo deve proporcionar a integração de todos os conhecimentos aí desenvolvidos, de forma interdisciplinar, transdisciplinar, intercultural, intertranscultural e transversal, baseando a aprendizagem nas vivências dos alunos".

Quanto ao diretor da escola, questionado sobre essa situação da integração curricular entre as bases regular e técnica, confirmou o que havia sido relatado pelos professores, como segue:

Realmente a gente tem uma falha no nosso processo de escola profissionalizante, nós não fazemos a integração do currículo, nós somos uma escola integral, no sentido de formação omnilateral do menino, mas a formação integrada, integrar currículo, uma disciplina $x$ vai interferir lá no curso técnico, isso para nós é uma falha muito grande da nossa escola, de não ter esse estudo (DIRETOR, Entrevista, 2020).

Ele ressalta que a escola é uma instituição que trabalha a formação do aluno de forma integral, porém falha no aspecto da educação integrada. É preciso trabalhar mais esses aspectos entre os eixos técnicos e regular, visto que a escola deveria ser uma instituição de educação integrada. Além do mais, a educação profissional apresenta nuances de semelhança com a educação integral, com uma base de mostrar a conexão dos conteúdos, todavia, na realidade em questão, isso não tem acontecido.

Quanto aos discentes, argumentam que "os professores olhem para os alunos, com mais empatia, afetividade. E tentem ter uma relação de mais harmonia e que saibam ouvir as opiniões dos alunos". (ESTUDANTE 3, Entrevista, 2020). Com essa afirmação, o aluno relata a importância de entender os princípios da educação integral: a necessidade de estar atento aos elementos e às singularidades sociais e formativas dos sujeitos, os professores da base comum dialogando com os professores da base técnica, os docentes e discentes desenvolvendo suas atividades em harmonia. 
Perguntou-se ao gestor quais os desafios de gerir uma escola de educação profissional, trabalhando a formação integral do educando. Ele assim se expressou:

Eu acho que formar uma pessoa de forma integral é muito difícil, porque a gente já pega esses meninos com 14, 15 anos, até mais, ele já vem com toda uma experiência de casa, com alguns medos, alguns desafios, e assim para moldar eles de forma integral, [...] tentando inserir ele da melhor forma possível nesse processo, e é muito difícil, [...] porque alguns alunos são bons em conteúdos. Geralmente, quando o aluno é bom, ele é bom em tudo, e quando é ruim, ruim no sentido não de pessoa, mas de atitudes difíceis, a gente sabe que tudo tem um porquê, às vezes esse menino é difícil porque ele não teve oportunidades (DIRETOR, Entrevista, 2020).

O gestor destaca que é muito difícil trabalhar a formação dos jovens de forma integral. Evidenciou-se, na sua fala, de certo modo, uma incompreensão do pressuposto da formação integral, considerando-a sinônimo de educação em tempo integral. A educação integral é marcada pela expansão das técnicas de ensino e aprendizagem, ampliando a concepção de mundo e não somente de tempo. Sobre esse aspecto, Gadotti (2009) ressalta que todas as escolas deveriam ser de educação integral, independentemente de serem de tempo integral.

Para trabalhar esse tipo de formação do discente, é importante ouvir seus anseios e percebêlos como peças fundamentais no processo de aprendizagem. Quando a escola trabalha colocando o aluno no centro, estimulando o protagonismo do discente nas práticas pedagógicas, ampliam-se as possibilidades dessa formação integral.

Buscando compreender como a instituição tem realizado essa escuta dos discentes, questionou-se aos estudantes como a gestão conversa com eles sobre os projetos escolares, se ela permite ou modifica esses projetos a partir das considerações deles. Um aluno expressou sua opinião da seguinte forma:

Creio que não existe uma efetivação entre a opinião dos alunos sobre os projetos e a gestão, quanto ao que os estudantes acham sobre o desenvolvimento das ações. Podendo ter essa comunicação por meio das avaliações de critérios, como, a forma como ocorreu o desenvolvimento, se foi proveitoso. [...] Então, seria a nossa avaliação, mas realmente, eles tentarem fazer a efetivação disso (ESTUDANTE I, Entrevista, 2020).

$\mathrm{Na}$ visão do aluno, não há uma efetivação das opiniões dos discentes. Ele sugere que seja realizada uma avaliação com os estudantes sobre o desenvolvimento das ações da escola e, a partir dessa avaliação, que se busque realizar as sugestões de forma efetiva. Com isso, percebe-se uma falha no processo de comunicação. A escola precisa possibilitar que esse elemento aconteça de modo efetivo, entendendo que, ao ouvir os anseios dos alunos, contribui para a efetivação da educação integral, suas bases e seus projetos. Dayrell (2016) destaca que é preciso ouvir os anseios dos jovens; a escuta ativa desses atores é importante para adequar conteúdos, ritmos e tempos à realidade juvenil. 
Compreendê-los como sujeitos de desejos, fazendo com que eles queiram mais e ampliem suas experiências.

$\mathrm{Na}$ sequência, perguntou-se aos discentes, quanto aos projetos desenvolvidos na escola, quais aqueles de que eles mais gostam e os que mais ajudam no desenvolvimento da aprendizagem. Nas falas, é possível perceber ênfase a projetos que promovem a interação entre eles mesmos.

La Hispanidad ${ }^{3}$, é visivel que os alunos executam com toda empolgação, junta-se a dinamização, através das apresentações artísticas, com o aprendizado, além dos conteúdos serem principalmente de assuntos que gostamos, [...]. Outro projeto que muito me chama atenção é o Geração da $\mathrm{Paz}^{4}$, pois é o momento que findamos o ano letivo e somos instigados a refletir sobre tudo que vivemos e a relevância das pessoas, dos acontecimentos na nossa vida! Quanto ao desenvolvimento da aprendizagem, diante dos que já pude participar, seria o Círculo de Leitura ${ }^{5}$, pois muitas vezes os alunos não têm interesse pela leitura, ou nem mesmo reservam tempo para tal finalidade, então quando tinha os encontros semanais na qual fazíamos a leitura, e depois a interpretação, em alguns aguçava o interesse em ler, [...] Mas vendo em âmbito geral, acredito que os alunos que fazem parte do Projeto de Monitoria ${ }^{6}$, estes são bem mais beneficiados, pois às vezes de aluno para aluno, tornase o aprendizado mais fácil, simples, e no momento que estamos ensinando também estamos aprendendo, que na minha opinião deveria ser expandido para toda escola (ESTUDANTE 2, Entrevista, 2020).

Fortificado pela fala de outro estudante, percebe-se que projetos que favorecem o protagonismo estudantil são bem aceitos pelos discentes:

Os projetos que desenvolvem a aprendizagem, considero que a Feira de Ciências porque são diversos temas trabalhados e apresentados pelos alunos, trazendo mais conhecimento, e as Células de Estudo, porque era uma forma de aprender em grupo e tirar dúvidas com os próprios colegas (ESTUDANTE 4, Entrevista, 2020).

Contrariamente, questionou-se também sobre quais projetos da escola eles não gostam e por quais motivos. Um aluno relata que o projeto que não gosta é um que versa sobre competências socioemocionais. De acordo com ele, "pela forma e dinâmica que ele ocorre, sendo por preenchimento de fichas durante o ano, sem possuir um direcionamento específico, devido os próprios professores não terem essa preparação psicológica, por vezes, não podendo contribuir diante a situação do aluno" (ESTUDANTE I, Entrevista, 2020). Este projeto é desenvolvido pelo Professor

\footnotetext{
3 Projeto de Espanhol que visa proporcionar aos estudantes uma imersão na cultura dos países que têm o espanhol como língua oficial, despertando o interesse pelo idioma.

${ }^{4} \mathrm{O}$ projeto tem o objetivo de mobilizar a sociedade para o compromisso de promover ações educativas e sociais voltadas para a valorização da vida e para a geração da paz.

${ }^{5}$ Projeto de incentivo à leitura; os alunos em um grande círculo conversam sobre as obras literárias.

6 Nesse projeto, os alunos são distribuídos em duplas ou em trios para realizarem atividades de forma colaborativa, são acompanhados pelo professor que media e facilita o processo de ensino e aprendizagem.
} 
Diretor de Turma, que faz o acompanhamento mais de perto de uma turma, no entanto, pela fala do discente, resume-se à parte burocrática: preenchimento de fichas e levantamento de dados.

Uma das premissas da educação integral é o aprimoramento do educando como pessoa humana, através de uma formação ética, com autonomia intelectual e pensamento crítico. A educação integral valoriza não só o desenvolvimento cognitivo, mas também o desenvolvimento emocional, social e cultural dos jovens atendidos. Sobre isso, um dos professores que atua diretamente com esse desenvolvimento na escola, relata:

Essas competências emocionais, é só um recurso do Estado, mas eu acho que não
ajuda muito, nunca ajudou, nunca veio um apoio. Eles respondem, a gente tem as
respostas, mas a gente faz o que com elas? Nada. A gente preenche uma planilha e
essa planilha vai para Crede', porque tem um setor que é responsável e pronto, até
hoje nunca teve uma resposta, quando eu pergunto a gestão, o que eu falo para esses
meninos, qual a resposta que eu dou para eles, aí falam que é para a gente saber um
pouco, como é que tá o emocional desses meninos, para a gente conversar, passar
um texto motivacional, só isso, mas se a gente fala assim, ah não adianta nada, aí a
gente é criticado, porque a gente tem que ser mais otimista, tá sendo muito negativo
com essa questão, e às vezes falam que a gente é do contra né. É como se a gente
não quisesse fazer o trabalho. Ano passado os alunos perguntavam demais: Pra que
isso? Vai vir alguém, vai vir um psicólogo, vem alguém fazer um acompanhamento,
vem alguém fazer alguma coisa com a gente? É só você, aí você passa o vídeo, você
conversa essas coisas e aí fica por isso mesmo. É muito complicado (PROFESSOR
NATUREZA, Entrevista, 2020).

Evidenciou-se que a fala do professor vai ao encontro ao que disse o aluno; falta uma formação, um direcionamento maior para o docente atuar sobre esse aspecto, trabalhando de forma mais efetiva as competências socioemocionais. Falta um retorno aos discentes quanto às problemáticas evidenciadas e os mesmos reclamam bastante. Embora os Professores Diretores de Turma se empenhem para realizar as atividades do projeto, percebe-se a limitação do seu poder de atuação.

Ainda sobre a questão dos projetos que são desenvolvidos pela escola e que os discentes argumentam não gostar, observa-se o que diz um estudante:

Na questão do projeto que eu não gosto, eu acho que o Aluno Nota 10 , porque quando nós somos premiados a gente fica muito feliz, a gente ver o esforço da família, porém, pensando de uma forma mais crítica, o Aluno Nota 10 é um projeto que tem em vista a meritocracia. E como dizia Mário Sérgio Cortela: A meritocracia se ela não for dada do ponto de partida de igualdade, então ela não é justa, tendo em vista que nós temos alunos de diversas realidades, diferentes, com embasamento teórico totalmente diferente, então não tem como medir esse aprendizado com esse projeto, através desse incentivo por nota. Acho muito interessante a questão da valorização da frequência, de quem lê, agora quando se fala em resultados por nota em si, acho que deixa um pouco a desejar esse projeto (ESTUDANTE 7, Entrevista, 2020).

\footnotetext{
7 Coordenadoria Regional de Desenvolvimento da Educação.
} 
Através do Projeto Aluno Nota 10, são premiadas as turmas mais frequentes, os alunos mais leitores e aqueles destaques em notas na base regular e na base técnica. Ao estimular a meritocracia, gera uma competitividade entre os sujeitos, o que, de certo modo, é contraditório à educação integral, pelo fato de desconsiderar os ritmos de aprendizagens dos discentes. $O$ estudante relata existir colegas com diferentes realidades, considerando injusta a meritocracia, uma vez que não é possível mensurar o aprendizado através de uma nota, visto que ela não parte de uma igualdade, ou seja, o projeto não é equânime.

Segundo Krawczyk (20I4), as escolas integrais se configuram como uma estratégia de proteção social, na promoção da equidade educacional, na potencialização do sucesso acadêmico dos discentes e na formação humana plena. $O$ que, de certo modo, vai na contramão da meritocracia e é destacado na fala do aluno. Por isso, é necessário a escola repensar o projeto, encontrando outras formas de valorizar a aprendizagem dos estudantes, sem necessariamente estimular a competitividade. Esse processo de valorização aconteceria de forma mais efetiva através da promoção de práticas que promovam a inclusão dos saberes, levando em conta os anseios desses jovens.

Perguntou-se aos estudantes como se sentem em relação aos professores da escola, se as metodologias de ensino adotadas os estimulam a pensar sobre a importância de aprender determinado conteúdo e o que mudariam na relação com as disciplinas. Um aluno argumentou:

Existem professores que nos fazem sentir acolhido por parte da escola, é perceptível, por eles serem pessoas que têm um grande contato com a gente durante o dia na escola, é por isso que tem essa relação de afeto e amizade, muitos fazem o papel de outros professores que eu já tive que nunca fizeram, e eu acho muito lindo esse sentimento de empatia, que por mais que o professor tenha uma patente mais alta que $\circ$ aluno, dentro da escola, ele não demonstra aquela superioridade, que quer mandar, que quer menosprezar, que quer humilhar, pelo contrário, eles ajudam ao máximo a gente (ESTUDANTE 6, Entrevista, 2020).

O aluno destaca uma boa relação entre docentes e discentes. Percebe-se uma relação de aprendizagem na horizontalidade, que favorece esse processo, quanto à questão das metodologias. Freire (2008) destaca que somente uma educação comprometida com a humanização possibilita romper com a relação verticalizada entre professores e estudantes. A prática pedagógica, caracterizada por princípios da educação libertadora, mediada pelo diálogo, valoriza a horizontalidade dos saberes, propiciando aos estudantes o desenvolvimento do senso crítico, contribuindo para uma formação integral. Ainda sobre esse aspecto, nota-se a visão de outro aluno:

Tem professores que têm metodologia excelente e dinâmica, e isso ajuda muito o aprendizado dos alunos. A metodologia que é boa para mim pode não ser boa para meu colega, por isso é importante a diversificação da metodologia, ou seja, os professores têm que ser criativos e têm que contextualizar a aula (ESTUDANTE 3, Entrevista, 2020). 
Entretanto, nem todos realizam essa diversificação, como expõe a fala de outro aluno, quando diz:

A maioria dos professores mantém uma mesma metodologia independente do conteúdo, não atraindo $\circ$ aluno. Pois por vezes o estudante se vê com a responsabilidade de apenas decorar e decodificar o conteúdo, sem se preocupar com entendimento do porquê de determinadas resoluções (ESTUDANTE I, Entrevista, 2020).

$\mathrm{Na}$ visão do aluno, muitas vezes, a aprendizagem acontece de forma mecânica, apenas como uma decodificação do conteúdo, sem um entendimento maior. Como a maioria dos professores tem uma resistência em modificar suas metodologias de ensino, isso colabora para a redução do interesse do aluno nas aulas. Sobre esse aspecto, Dayrell (2016) argumenta que a escola precisa se adequar a uma "pedagogia da juventude", o que implica alinhar os ritmos dos processos educativos aos anseios desses jovens. Nessa mesma contextualização, outro estudante ressalta:

O professor deveria ser inovador, existem professores de excelência na escola, que tem o conhecimento bem rico, porém com algumas metodologias, que começam a ficar ultrapassadas, não querendo dizer que o professor tem que ser moderninho, mas tem que ter a sensibilidade de ver, que quanto melhor a metodologia em relação ao entrosamento com o aluno, vai ficar mais fácil o processo de aprendizado. $\mathrm{Na}$ escola existem muitos professores que nos fazem sentir realmente parte da escola, principalmente pela forma como eles nos tratam, pelas atividades, não atividades em si, mas as atividades em geral que são feitas com os alunos na escola e assim, infelizmente existem alguns professores que já caíram naquela rotina e já estão habituados aquele mesmo comodismo, de chegar na aula e dar os conteúdos (ESTUDANTE 7, Entrevista, 2020).

O discente relata que a escola possui excelentes educadores, porém, alguns estão habituados com a rotina e não modificam suas práticas. Para Dias (2016), a escola deve apresentar múltiplas metodologias com foco na aprendizagem dos educandos, para que essa aprendizagem seja significativa para esses jovens. $O$ autor destaca que o jovem e o seu projeto de vida devem estar no centro do processo.

Perguntou-se aos docentes sobre a importância do protagonismo discente e a escuta dos anseios dos estudantes. Observa-se:

\footnotetext{
Esse protagonismo discente impacta sim nos resultados internos e também externos. O que é uma forma desses alunos terem revisões, estudos extras com os próprios colegas, muitas vezes o que o aluno não compreende com a explicação do professor ele compreende com a explicação do colega. [...] Em relação aos anseios dos alunos[...], é interessante sim ouvir, porque já que que a educação, a escola é um local onde se favorece o desenvolvimento, se contribui para o desenvolvimento dessa democracia. Então, ouvir os gestores, os professores e os alunos, isso contribui para uma educação de melhor qualidade. Desde que também este ouvir os alunos não seja algo que tire a autonomia dos professores[...] (PROFESSOR LINGUAGENS, Entrevista, 2020).
} 
Por outro lado, um segundo docente destaca ser positiva a questão da monitoria, porém, segundo ele, são atividades voltadas às questões dos resultados. Ademais, considero importante ouvir os anseios dos discentes, mas diz ser inviável eles avaliarem se o conteúdo ministrado e a metodologia utilizada são adequados, visto que pressupõe que o professor tenha formação para definir isso (PROFESSOR LINGUAGENS, Entrevista, 2020).

Evidenciou-se que, a despeito de os docentes considerarem importante o protagonismo discente, há uma certa resistência de alguns deles, acerca das críticas e das sugestões realizadas pelos alunos sobre o aprimoramento das práticas pedagógicas, o que contraria a ideia de Freire (2019, p. III), para quem "o educador que escuta aprende a difícil lição de transformar o seu discurso, às vezes necessário, ao aluno, em uma fala com ele". Ainda nas palavras do autor, acrescenta-se que "é pensando criticamente a prática de hoje ou de ontem que se pode melhorar a próxima prática” (p. 40).

Frente aos resultados da pesquisa, elencaram-se alguns dados como potencialidades da educação integral, quais sejam: os alunos relatam a importância da empatia e da afetividade, que as relações devem ser harmoniosas, que os docentes devem estar abertos a ouvir suas opiniões e sugestões. Ainda entendendo os princípios desse tipo de educação, considerando a atenção aos elementos dos sujeitos, os professores da base comum devem dialogar com os professores da base técnica (e vice-versa); os docentes e os discentes devem desenvolver suas atividades em harmonia.

Por outro lado, apresentar-se-ão algumas fragilidades encontradas na investigação. Essas lacunas estão detalhadas, a seguir, no quadro I, como também as proposições de ações com vistas a superar essas problemáticas.

Quadro I - Lacunas encontradas na Pesquisa de Campo

\begin{tabular}{|c|c|c|}
\hline $\begin{array}{c}\text { PONTO } \\
\text { ANALISADO }\end{array}$ & PROBLEMA & $\begin{array}{l}\text { AÇÕES PASSÍVEIS DE } \\
\text { INTERVENÇÃO }\end{array}$ \\
\hline \multirow{4}{*}{$\begin{array}{l}\text { Educação } \text { de } \\
\text { Tempo Integral e } \\
\text { Integrada na } \\
\text { perspectiva da } \\
\text { Formação Integral }\end{array}$} & $\begin{array}{l}\text { Forte separação entre o eixo profissional e o } \\
\text { eixo regular; com uma diferenciação no } \\
\text { tratamento, os dois eixos deveriam ser tratados } \\
\text { com igualdades; }\end{array}$ & $\begin{array}{l}\text { Propor reuniões pedagógicas de integração } \\
\text { entre os eixos profissional e regular. }\end{array}$ \\
\hline & $\begin{array}{l}\text { Para o gestor, a escola não realiza a integração } \\
\text { curricular. Este ressalta que a escola é uma } \\
\text { instituição que trabalha a formação do aluno de } \\
\text { forma integral, entretanto ela falha no aspecto } \\
\text { da educação integrada; }\end{array}$ & $\begin{array}{l}\text { Pensar estratégias de integração curricular } \\
\text { com os atores da instituição, através de } \\
\text { práticas e atividades que ampliem essa } \\
\text { integração, por meio de um estudo da } \\
\text { grade curricular dos cursos ofertados pela } \\
\text { instituição. }\end{array}$ \\
\hline & $\begin{array}{l}\text { Percebemos uma falha no processo de } \\
\text { comunicação. A escola precisa possibilitar que } \\
\text { esse elemento aconteça de modo efetivo e que } \\
\text { esses atores se sintam ouvidos e pertencentes } \\
\text { ao processo; }\end{array}$ & $\begin{array}{l}\text { Fomentar canais de comunicação e escuta } \\
\text { ativa dos diferentes atores da escola, de } \\
\text { forma que as ações desenvolvidas na escola } \\
\text { sejam refletidas e aprimoradas por todos } \\
\text { os atores do ambiente estudantil. }\end{array}$ \\
\hline & $\begin{array}{l}\text { Os estudantes reclamam do desenvolvimento } \\
\text { do projeto das competências socioemocionais, } \\
\text { que se resume à parte burocrática, ao } \\
\text { preenchimento de fichas e ao levantamento de }\end{array}$ & $\begin{array}{l}\text { Não podemos interferir na implementação } \\
\text { da disciplina, mas podemos discutir e } \\
\text { repensar sua forma de atuação na escola. }\end{array}$ \\
\hline
\end{tabular}




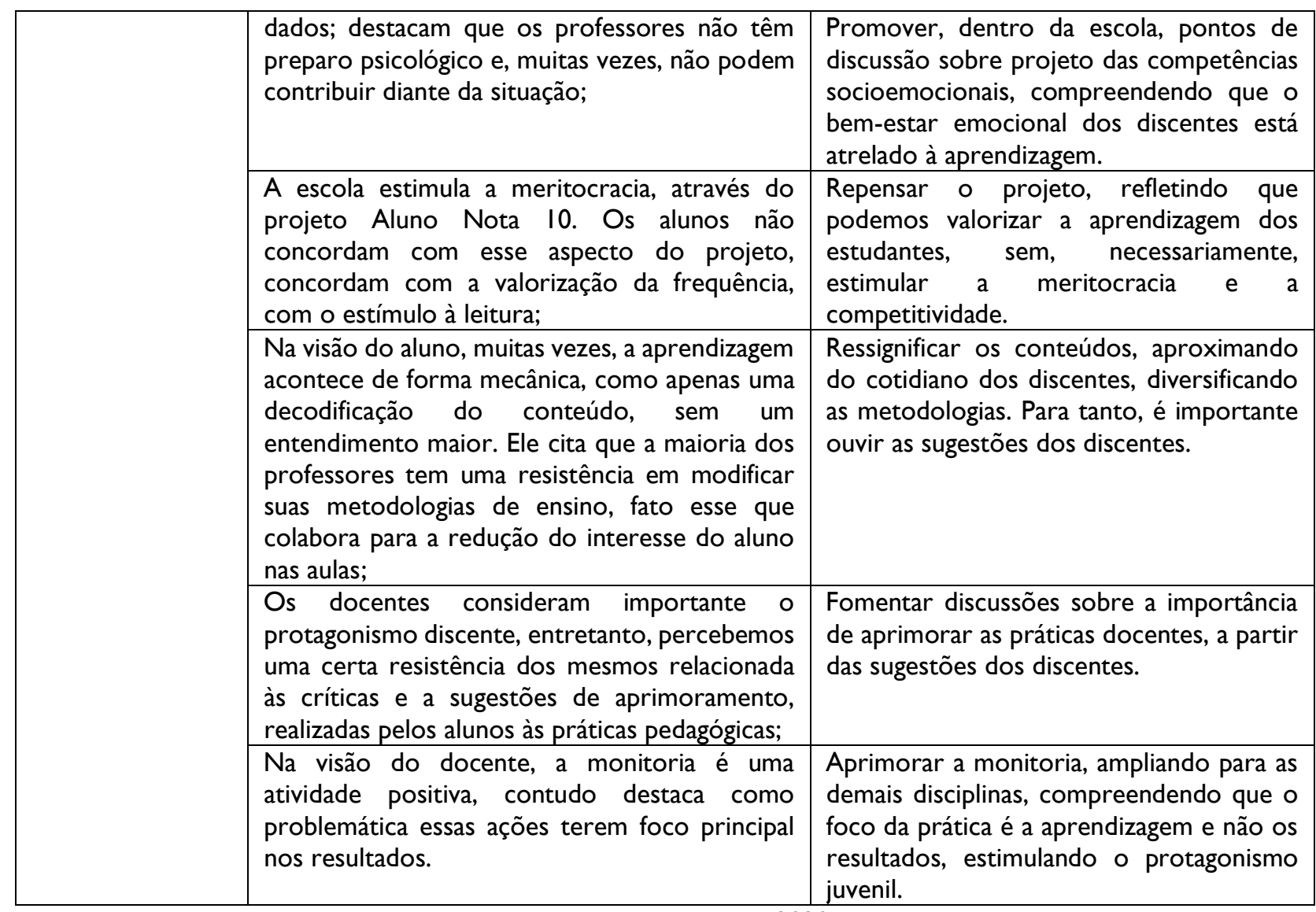

Fonte: Elaborado pelo autor, 2020.

Diante das ponderações apresentadas, pontua-se a necessidade de se pensar estratégias que ampliem a integração dos professores do eixo profissional e do eixo regular, através de práticas pedagógicas e atividades que possibilitem uma maior aproximação, contribuindo para a efetivação de uma educação voltada para a formação integral dos educandos.

\section{Considerações Finais}

O presente trabalho buscou investigar a relevância da integração curricular na perspectiva da formação integral em uma escola de educação profissional no estado do Ceará. Para tanto, investigouse como a integração curricular entre as bases técnica e regular tem acontecido na instituição e como a Educação Profissional Integrada tem se desenvolvido, na perspectiva da formação integral dos jovens atendidos por essa modalidade de ensino.

A ideia do Ensino Médio Integrado é que não seja apenas um ensino médio em que o aluno aprenda os conhecimentos curriculares de uma forma fragmentada, mas que ele possa ter acesso a uma educação básica e também a uma educação profissional em que possa compreender as técnicas, as tecnologias e a ciência por trás dos diversos ofícios e que não seja apenas uma justaposição do 
ensino médio com um curso básico profissional, que eles sejam articulados e que tenham uma integração, que faça jus ao termo Ensino Médio Integrado.

A partir dos resultados da pesquisa, fica evidente o distanciamento entre a educação básica geral e a educação profissional, permanecendo essa dualidade. Percebe-se uma dificuldade de implementação de uma Educação Profissional Integrada que seja efetiva no sentido dessa articulação, para que o sujeito seja formado na sua ampla capacidade física, intelectual e tecnológica. Esse distanciamento dificulta a integração curricular e o trabalho com esses jovens na perspectiva da formação integral. Destaca-se a necessidade de se pensar estratégias e práticas que ampliem essa integração, primordialmente, por meio do estudo dos currículos dos cursos ofertados pela instituição e pelas reuniões pedagógicas de integração entre os eixos profissional e regular.

A partir do referencial teórico utilizado na pesquisa, buscou-se levantar evidências se as práticas desenvolvidas na instituição eram reflexo de um trabalho integrado dos atores da escola, atentando para seus elementos singulares e para suas características sociais e formativas. Como também a discussão sobre educação integral, entendendo que os anseios dos jovens devem ser considerados e incorporados ao processo.

Por fim, o estudo enfatiza a importância da educação na perspectiva da formação integral, tendo em vista que as práticas pedagógicas desenvolvidas no âmbito da instituição escolar precisam ser significativas e estar centradas, principalmente, na atuação dos jovens, os quais devem ser protagonistas da ação. O foco principal do trabalho docente, portanto, deve ser a formação integral dos jovens.

\section{Referências}

CIAVATTA, M. O ensino integrado, a politécnica e a educação omnilateral. Por que lutamos? Trabalho \& Educação, Belo Horizonte, MG, v. 23, n. I, p. 187-205, abr. 2014. Disponível em: https://periodicos.ufmg.br/index.php/trabedu/article/view/9303/6679. Acesso em: 20 de janeiro de 2021 .

DARCY, Ribeiro: a educação como legado. [S.I.]: Grupo Editorial Global, São Paulo, 20I7. I vídeo (I Imin. e 49s). Disponível em: https://youtu.be/TI MemL_Pmjl. Acesso em: 28 out. 2019.

DAYRELL, J. T. A escola "faz" as juventudes? Reflexões em torno da socialização juvenil. Educ. Soc., Campinas, SP, v. 28, n. 100, p. I I05-I I 28, out. 2007. Disponível em: https://doi: 10.1590 / S0 I0I73302007000300022. Acesso em: 2 mar. 2020.

DAYRELL, J. T. (org.). Por uma pedagogia das juventudes: experiências educativas do Observatório da Juventude da UFMG. Belo Horizonte: Mazza Edições, 2016.

DIAS, M. R. O solo educacional de um projeto e suas sementes. Escola do Herval: a teimosia da esperança. Juiz de Fora: CAEd: FADEPE, 2016. 73-85 p.

FREIRE, P. Educação como prática da liberdade. 3I. ed. Rio de Janeiro: Paz e Terra, 2008. I58 P.

Olhar de professor, Ponta Grossa, v. 25, p. I-19, e-17372.010, 2022.

Disponível em <https://revistas2.uepg.br/index.php/olhardeprofessor> 
FREIRE, P. Pedagogia da autonomia: saberes necessários à prática educativa. 62. ed. São Paulo: Paz e Terra, 2019.

GADOTTI, M. Educação integral no Brasil: inovações em processo. São Paulo: Editora e Livraria Instituto Paulo Freire, 2009.

KRAWCZYK, N. Reflexão sobre alguns desafios do ensino médio no Brasil hoje. Cad. Pesquisa, [on-line], v. 4I, n. I44, p. 752-769, 20I I. Disponível em: https://doi.org/I0.I590/S0 I00I57420 I I000300006. Acesso em: 20 dez. 2019.

KRAWCZYK, N. Ensino médio: empresários dão as cartas na escola pública. Educ. Soc., Campinas, SP, v. 35, n. I26, p. 2I-4I, 20I4. Disponível em: https://doi.org/I0.I590/S0I0I-733020I4000I00002. Acesso em: 20 dez. 2019.

MAINARDES, J.; CURY, C. R. J. Ética na pesquisa: princípios gerais. In: Associação Nacional de PósGraduação e Pesquisa em Educação. Ética e pesquisa em Educação: subsídios. Rio de Janeiro: ANPED, 2019. P. 24-29 Disponível em:

https://anped.org.br/sites/default/files/images/etica_e_pesquisa_em_educacao_-_isbn_final.pdf. Acesso em: 20 jan. 2021.

RAMOS, M. N. Verbete Currículo Integrado. In: Fundação Oswaldo Cruz. Dicionário da Educação Profissional em Saúde. Rio de Janeiro: Escola Politécnica de Saúde Joaquim Venâncio, 2009. [n.p.]. Disponível em: http://www.sites.epsjv.fiocruz.br/dicionario/verbetes/curint.html. Acesso em 20 de janeiro de 2021 .

RAMOS, M. N. Possibilidades e desafios na organização do currículo integrado. In: FRIGOTTO, G.; CIAVATTA, M.; RAMOS, M. (orgs.). Ensino Médio Integrado: concepções e contradições. 2. ed. São Paulo: Cortez, 2010. p. 106-127.

VERGARA, S. C. Métodos de coleta de dados no campo. São Paulo: Editora Atlas, 2009.

Recebido em: 27 de janeiro de 2021 .

Versão corrigida recebida em: 24 de maio de 2021.

Aceito em: 24 de maio de 2021.

Publicado online em: 18 de fevereiro de 2022. 